\title{
Farbe in der Natur
}

\author{
HiLKe STEINECKE
}

Unter diesem Motto lief vom 14. Mai bis 1. November die große Informationsausstellung des Jahres 2009 im Palmengarten. Mit einer Vorlaufzeit von rund drei Jahren war diesmal die Vorbereitung relativ lang. Die Ausstellung war schon für das Jahr 2008 geplant, doch durch den Umbau des Gesellschaftshauses und der Galerien am Palmenhaus musste sie um ein Jahr verschoben werden. Die Ausstellungen des Jahres 2009 wurden ausnahmsweise an für den Palmengarten neuen Orten gezeigt: Auf der Spielwiese wurde für ein Jahr ein Leihgewächshaus errichtet, das sich vorher auf diversen Landesgartenschauen bewährt hatte. Der Aufbau dieses Glashauses mitsamt seiner technischen Einrichtungen wie Strom- und Wasserversorgung, Klimatisierung sowie Bodenbelag war sehr aufwändig. Nach der Gartenmesse und der Orchideen-Ausstellung im Frühling beherbergte das Gewächshaus schließlich für den Rest des Jahres die Ausstellung „Farbe in der Natur“.

Die als Wanderausstellung konzipierte Ausstellung ist grob in drei Themenbereiche gegliedert. Zu Beginn erfährt der Besucher einiges darüber, was Licht und Farbe sind und wie wir Farbe wahrnehmen. Es können hier z. B. drei Zelte in den Farben Rot, Blau und Gelb betreten und die Empfindungen in diesen verschiedenen monochromen Räumen notiert werden. Im zweiten Teil wird die Vielfalt der Farben im Pflanzenreich vorgestellt. Chlorophyll, Anthocyane, Karotine, Betalaine und Flavone werden erläutert. Ihre biologische Bedeutung, auch im Hinblick auf Bestäubungs- und Verbreitungsbiologie, werden erklärt. Ein weiterer Schwerpunkt der Ausstellung ist der Anwendungsaspekt, wobei hier vor allem Färbepflanzen für Textilien und pflanzliche Lebensmittelfarben einen Platz finden. Beachtens-

Abb. 1: Pavillon mit Seidentüchern, die mit diversen Pflanzenfarben gefärbt wurden.

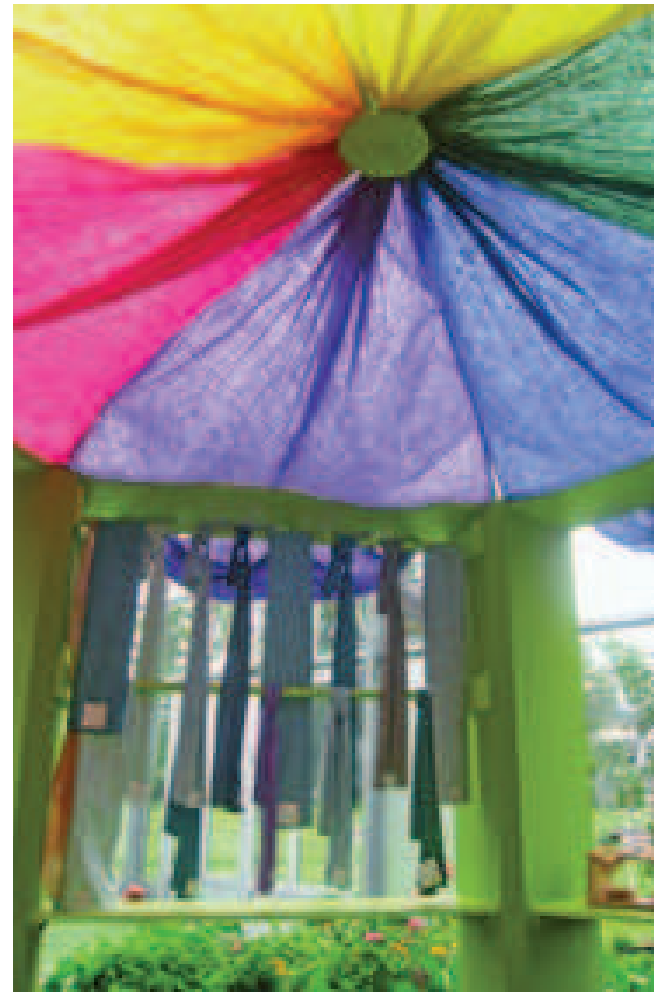

wert ist die Vielfalt an Seidentüchern, die in mühsamer Handarbeit mit diversen Pflanzen extra für die Ausstellung gefärbt wurden. Fotos bunter Blumenrabatten geben einen kleinen Einblick in die Gestaltung mit Farbe im Garten.

Es ist uns generell ein Anliegen, dass in Ausstellungen viel ausprobiert und geschaut werden kann und es interaktive Stationen gibt, die Erwachsene sowie Kinder ansprechen. So können hier beispielsweise an Fotovorhängen, die mit Kärtchen verschiedener Farben bestückt sind, diejenigen Farben herausgesucht werden, die nach Pflanzen benannt sind wie z. B. Kirschrot, Lavendelblau, Zitronengelb oder Tannengrün. Auf einem über $4 \mathrm{~m}$ breiten und 2,50 $\mathrm{m}$ langen Banner sind mehr als 200 Blüten-Fotos in farblicher Sortierung abgebildet. Es ist eine span- 

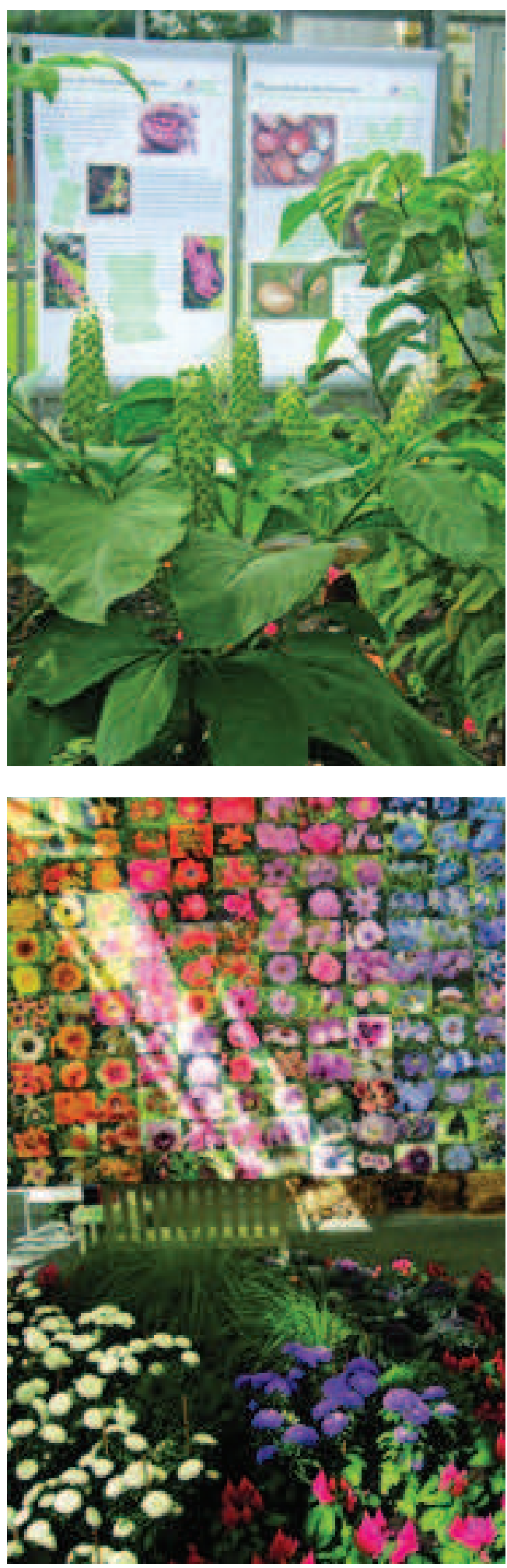

nende Herausforderung für die Besucherinnen und Besucher, die beiden Bildpärchen herauszufinden, die jeweils ein identisches Motiv zeigen.

Die Informationen finden sich auf 35 Textilbannern im Format $90 \mathrm{mal} 140 \mathrm{~cm}$. Ergänzend dazu sind ein 100-seitiges Sonderheft sowie eine Kinder-Arbeitsmappe erschienen.

Uns war sehr daran gelegen, dass sich die Ausstellung mit der Zeit etwas veränderte, so dass es immer wieder aufs Neue interessant war, die Ausstellung zu besuchen. So ergab sich im Laufe des Jahres ein unterschiedlicher Aspekt der zu den Informationen passend gepflanzten Beete: Färbepflanzen und Pflanzen besonderer Blütenund Blattfarben blühten, verblühten und wuchsen in die Höhe. Da die Erntedankausstellung 2009 in die Farbausstellung integriert wurde, leuchteten die Beete ab Mitte September vor allem in den Farben Orange und Violett auf (Celosien, Sonnenblumen, Zierpaprika, Kürbisse etc.). Die ebenfalls in der Farbausstellung untergebrachte Chrysanthemen-Schau brachte gegen Ende der Saison wieder weitere schöne Farben in das Gewächshaus.

Abwechslung boten auch die verschiedenen Kunst- und Bilder-Ausstellungen. Große und sogar auch internationale Resonanz gab es auf die beiden Fotowettbewerbe, die als Ergänzung der „Farbe in der Natur" durchgeführt wurden. Während bei dem von einer regionalen Zeitung unterstützten Wettbewerb auch viele Motive aus dem Palmengarten eingeschickt wurden, erhielt die überregionale Zeitschrift „Natur Foto“ rund 1600 Einsendungen mit Motiven aus aller Welt. In den letzten Ausstellungswochen wurden die jeweils 20 besten Fotos beider Wettbewerbe im Palmengarten ausgestellt. Für den Fall, dass Farben auch den Appetit anregen, sorgten jedes

Abb. 2 (oben): Ein besonderer Reiz der PalmengartenAusstellungen besteht darin, dass auch lebende Pflanzen, die zum Thema passen, gezeigt werden können. Hier eine Kermesbeere vor den Tafeln zu pflanzlichen Lebensmittelfarben.

Abb. 3 (unten): Poster mit über 200 Blütenfotos hinter einem Pflanzenbeet, das zur Erntedankausstellung mit Blumen des Herbstes neu gestaltet wurde. 


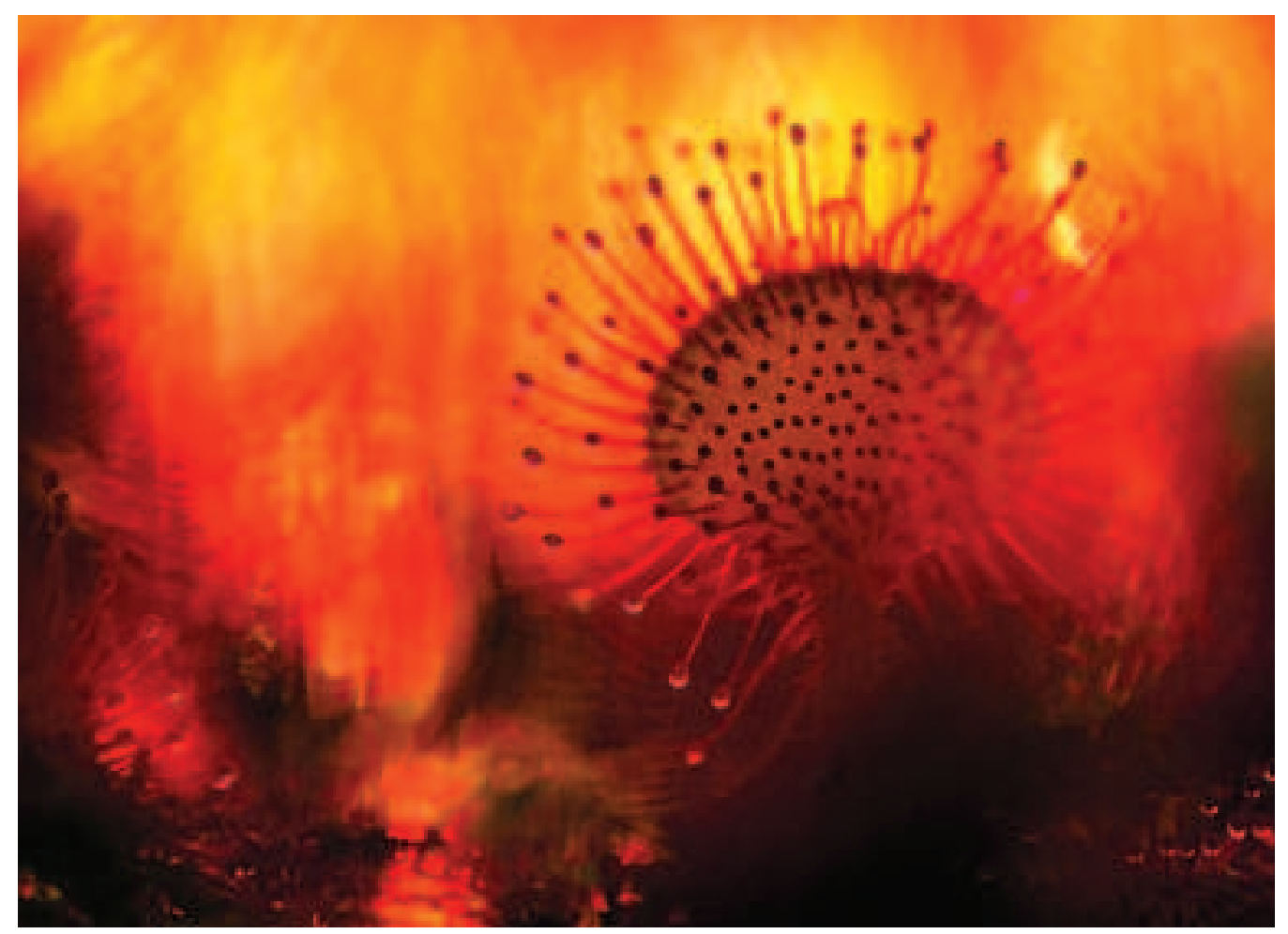

Wochenende ein Stand eines Reformhauses sowie eines Bio-Eis-Herstellers für kulinarischbunte Spezialitäten. An ausgewählten Terminen wurden zusätzlich bunte tropische Früchte zum Verzehr angeboten.

Das Thema Farbe zog sich während des Jahres durch viele Aktivitäten, was das umfangreiche Rahmenprogramm zur Ausstellung belegt. Auch im Freiland des Palmengartens war es dieses Jahr besonders farbig. Die Sommerflorbeete wurden passend zur Ausstellung angelegt, so gab es im Eingangsbereich ein gelbes, weißes, rotes und blaues Beet. Im Freiland war ein Rundgang zu gestalterischen Themen ausgewiesen. Die $20 \mathrm{Ta}-$ feln im A3-Format sind wetterbeständig und auf Plexiglas gedruckt.

Abb. 4: Sonnentau. Eines der Siegerbilder des Fotowettbewerbs in Zusammenarbeit mit der Zeitschrift „Natur Foto“. Die auf Kunststoff-Platten gedruckten Siegerfotos können ausgeliehen werden.
Da die Ausstellung als Wanderausstellung angelegt ist, kann sie vom Palmengarten ausgeliehen werden. Infobanner für innen, einzelne $\mathrm{Vi}$ trineninhalte sowie Freilandtafeln und gegebenenfalls Ausstellungskataloge sowie Kindermappen können zur Verfügung gestellt werden. Einige Objekte, insbesondere Farbmischpult, farbige Zelte oder mittelalterlicher Färbeladen und andere sind Teile der Ausstellung Vivacolor, die vom Staatlichen Museum für Naturkunde Stuttgart im Schloss Rosenstein konzipiert wurde. Ausleihbedingungen für diese Objekte müssen in Stuttgart erfragt werden.

Wir freuen uns darüber, dass die „Farbe in der Natur“ viele Menschen im Palmengarten erfreut hat und die Ausstellung schon 2010 auf die Reise in den Botanischen Garten Köln geht. 